• 研究报告・

\title{
莲品种DNA指纹图谱的构建
}

\author{
薛建华 ${ }^{*} \quad$ 姜 莉 ${ }^{2 \#}$ 马晓林 ${ }^{2} \quad$ 㱙艳红 $^{1} \quad$ 赵思晨 $^{2}$ 马克平 ${ }^{1}$ \\ 1 (中国科学院植物研究所植被与环境变化国家重点实验室, 北京 100093) \\ 2 (北京市海淀区圆明园管理处，北京 100084)
}

\begin{abstract}
摘要: 为了克服单纯依据形态特性鉴定品种的局限性, 我们开展了莲品种DNA指纹图谱构建研究, 旨在对其品种 的快速准确鉴定及专利权保护等起一定作用。本研究以圆明园保存的 72 个莲品种为实验材料, 用来自不同地点的 1,409份野生莲(Nelumbo nucifera)和58份美洲黄莲(N. lutea)群体样本作遗传背景参照。从104对核微卫星引物 (nSSR)中篮选出15对, 从17对叶绿体微卫星(cPSSR)引物中篮选出2对, 共17对引物作为72个莲品种DNA指纹鉴定 的条码。15对nSSR引物共检测到94个等位基因(平均6.27个), 其中11个属于美洲黄莲, 65个属于野生莲, 18个不能 区分; 多态信息含量 $(P I C)$ 介于0.3899-0.8023之间 (平均0.5748)。2对cpSSR引物共检测到13个单倍型, 其中9个属 于野生莲, 4 个属于美洲黄莲。全部17对引物标记结果显示, 共有19个品种含有美洲黄莲遗传组分, 其中 8 个母系来 源于美洲黄莲; 有 36 个品种(涉及12对引物)具有至少1个特有基因型; 最少8对引物组合可完全区分开68个品种。有 2组共4个品种组内全部17对引物均不能区分。本研究通过核心引物组合法使68个莲品种获得特异性DNA指纹。推 荐13对nSSR和2对 cpSSR共15对引物作为莲品种鉴定的核心条码, 并建议将形态特征与DNA指纹相结合作为莲品 种的鉴定标准。
\end{abstract}

关键词: DNA指纹; 微卫星; Nelumbo；品种鉴定；分子身份证

\section{Identification of lotus cultivars using DNA fingerprinting}

\author{
Jianhua Xue ${ }^{1 *}$, Li Jiang ${ }^{2 \#}$, Xiaolin Ma², Yanhong Bing ${ }^{1}$, Sichen $\mathrm{Zhao}^{2}$, Keping $\mathrm{Ma}^{1}$ \\ 1 State Key Laboratory of Vegetation and Environmental Change, Institute of Botany, Chinese Academy of Sciences, Bei- \\ jing 100093 \\ 2 Yuanmingyuan Administration, Beijing 100084
}

\begin{abstract}
DNA fingerprinting is a fast and accurate method for cultivar identification, which can overcome the limitation of morphological traits. We used DNA fingerprinting to identify 72 lotus (Nelumbo) cultivars collected from the Resources Garden of the Yuanmingyuan Park in Beijing. We used 1,409 samples of $N$. nucifera and 58 samples of $N$. lutea as a genetic background reference. Fifteen out of 104 pairs of nucleus microsatellite primers (nSSR) and 2 out of 17 pairs of chloroplast microsatellite primers (cpSSR), for a total of 17 pairs of fluorescent primers, were selected as the barcode for fingerprint identification of the 72 lotus cultivars. For the 15 nSSR primers, 94 alleles were examined (with an average of 6.27). Out of the 94 alleles, 11 belong to $N$. lutea, 65 belong to $N$. nucifera, and the remaining 18 alleles could not be identified. The polymorphism information content (PIC) range between 0.3899 and 0.8023 , with an average value of 0.5748 . For the two pairs of cpSSR primers, 13 haplotypes were examined. Among them, 9 haplotypes belong to $N$. nucifera and 4 haplotypes belong to $N$. lutea. Results of identification of all 17 pairs of primer markers showed that 19 cultivars included genes from $N$. lutea, and 8 cultivars had female parents from $N$. lutea. There were 36 cultivars (using 12 pairs of primers) which had at least one unique genotype. With a minimum of 8 pairs of primers, 68 cultivars could be distinguished. Among the 72 cultivars, four cultivars in two groups could not be distinguished based on the whole set of 17 primers. Using the core primer combination method, we developed specific DNA fingerprints for each of the 68 lotus cultivars. Based on the above re-
\end{abstract}

收稿日期: 2015-06-08 ; 接受日期: 2015-09-13

基金项目：国家自然科学基金(31270262)、科技基础性工作专项(2013FY112300)、北京市海淀区科委项目(K2012004S)

\# 共同第一作者 Equally contributed to this paper

* 通讯作者 Author for correspondence. E-mail: xuejianhua@ibcas.ac.cn 
sults, we recommended 15 pairs of primers including 13 pairs of nSSR and 2 pairs of cpSSR as the core barcode for lotus cultivar identification.

Key words: DNA fingerprint; microsatellites; Nelumbo; cultivar identification; molecular ID

莲科发现最早的化石是在早白严纪劳亚古陆 的中纬度地区，第三纪广布于欧亚大陆和北美洲, 共5个化石属约 30 个种( $\mathrm{Li}$ et al, 2014)。现仅存莲属 (Nelumbo) 2 个种, 即分布于亚洲和澳大利亚北部的 莲 (Nelumbo nucifera) 和北美洲的美洲黄莲 $(N$. lutea)。因此, 莲属被认为是子遗植物 (吴征篮等, 2003)。中国是莲的分布和栽培中心, 拥有世界上最 丰富的种质资源, 已有2,000多年的栽培历史, 目前 有800多个栽培品种(王其超和张行言, 2005; 张行 言等, 2011)。莲作为重要的资源植物, 具有食用、 药用、观赏和净化水体等价值, 还蕴藏着丰富的宗 教和文化内涵, 倍受人们的喜爱。野生莲被《国家 重点保护野生植物名录(第一批)》列为II级保护植 物, 品种莲也被列入 《中华人民共和国农业植物新 品种保护名录(第八批)》。

一直以来, 人们对莲品种的分类主要根据形态 特性, 如株形大小、花瓣多少、花色和心皮的瓣化 程度等。这种方法形象直观, 操作简便, 便于推广。 然而, 单纯依据形态鉴定有一定局限性, 如: 环境 条件变化会使品种表型出现一定可塑性, 导致鉴定 标准的界限很难把握; 鉴定时间受品种不同生活史 阶段限制; 不能推测品种间的遗传关系; 等等。因 此, 难免出现同物异名或同名异物及谱系关系不清 等问题。例如, 起源于中国的“千瓣莲” (王其超和张 行言, 2005), 引植到日本后被改称为 ‘妙莲’(Miura \& Ikegami, 2012); 在中国学者(王其超和张行言, 2005)和日本学者(Miura \& Ikegami, 2012)编著的品 种图志中, ‘孙文莲’形态特征完全不同。这些问题影 响了莲种质资源开发利用和保护的进程。

DNA指纹鉴定技术的应用, 为实现植物品种的 精准鉴定开辟了一条新途径。利用物种基因组中进 化速率较快的多个微卫星(或称简单重复序列 simple sequence repeat, SSR)位点的组合, 形成具有 个体特异性的DNA多态性, 其对个体识别能力足以 与人类指纹相媲美, 还可以转换成数字代码, 类似 人的身份证号码。因此, 被称为DNA指纹或分子身 份证。这个技术由英国遗传学家Jeffreys (1985a, b)
发明，最先用于获得人类的个体特异性遗传身份 证，后来被广泛用于亲子鉴定、司法鉴定和考古研 究等众多领域中。DNA指纹鉴定技术在植物品种真 实性、一致性和稳定性鉴定方面得到较好的推广应 用。它揭示遗传物质本身的变异, 不受外界环境和 人为因素等影响, 还可实现时时鉴定。国际植物新 品种保护联盟(International Union for the Protection of New Varieties of Plants, UPOV)于2005年承认植 物品种分子测试结果作为品种鉴定的辅助手段(赵 久然和王凤格, 2009)。2007-2014年, 我国农业部已 颁布了小麦(NY/T 2470-2013)、玉米(NY/T 14322014)、水稻(NY/T 1433-2014)、大豆(NY/T 25952014)、西瓜(NY/T 2472-2013)、百合 $(N Y / T$ 24772013)和苹果(NY/T 2478-2013)等15种作物DNA的 指纹鉴定技术行业标准。然而, 重要资源植物莲品 种的DNA指纹鉴定工作尚处于起步阶段。

本研究通过双亲遗传核微卫星(nSSR)和母系 遗传的叶绿体微卫星(cpSSR)标记相结合, 对圆明 园保存的 72 个莲品种材料进行分子标记, 篮选扩增 效果好、多态性高的引物作为莲品种鉴定的条码, 构建DNA指纹图谱数据库。将DNA指纹与形态特征 相结合作为莲品种的鉴定标准, 有助于解决目前品 种分类方面存在的问题，揭示品种间的遗传关系， 对规范分类管理、新品种培育和品种权的保护都有 重要意义。

\section{1 材料与方法}

\section{1 材料来源}

2013年我们从中国荷花研究中心(武汉)引植 120 个莲品种(每个品种 3 只种藕)于圆明园的资源围 中。以《中国荷花品种图志》(王其超和张行言, 2005) 和《中国荷花新品种图志I》(张行言等, 2011)中描 述的品种特性为标准, 进行连续 2 年的形态鉴定, 拍摄图片，去除死亡、未能开花、表型错误和同一 品种3份样本间基因型不一致的样品后, 剩余 72 个 品种作为本研究的实验材料(附录1, 图1)。为了区分 种间杂交起源的品种, 我们选取了来自俄罗斯里海 
和远东、印度尼西亚、斯里兰卡、越南、柬埔寨、 中国黑龙江流域、吉林珲春图门江流域、河北白洋 淀、山东微山湖、湖北洪湖和长湖、云南石屏县异 龙湖等地的1,409份野生莲群体样本和来自美国北 卡罗莱那州和德克萨斯州的 58 份美洲黄莲, 共 1,467份样品的基因型作为遗传背景参照。所有样品 均采集新鲜叶片, 迅速干燥备用。

\section{2 微卫星引物的篮选}

从中国黑龙江省、俄罗斯里海和斯里兰卡3个 不同地理分布区野生莲群体材料中随机各选4份(共 12份), 从美国德克萨斯州美洲黄莲群体材料中随 机选取4份, 共16份样品作为篮选引物的DNA样本。 从Yang等(2012)基于古莲全基因组中开发的500对 核微卫星(nSSR)引物中选择了 76对, 标记了16个样 品, 最终选择扩增效果好、有种间和种内多态性、 引物间不锁群的 16 对引物, 还从我们(Tian et al, 2008)自主开发的17对引物中优选2对, 从Kubo等 (2009)开发的11对引物中优选2对, 共20对nSSR引 物用于正式实验。从莲科叶绿体全基因组中开发的 17对多态性cpSSR引物(Xue et al, 2012)中优选6对 进行正式实验。

\subsection{SSR分子标记}

用天根生物技术公司生产的植物基因组DNA 提取试剂盒(DP305)提取干燥叶片中的总DNA。用 美国Quawell超微量分光光度计 Q6000检测DNA纯 度(光密度OD 260/280值约为 1.8)。PCR反应模板 DNA浓度10 ng左右。PCR反应试剂用天根生物技术 公司生产的2×Taq PCR MasterMix (KT201)。委托上 海生工生物工程有限公司合成在 $5^{\prime}$ 端进行 4 种苂光 修饰 (FAM, HEX, ROX 和 TAMRA) 引物。用 Eppendorf PCR仪进行 PCR扩增。PCR扩增程序: $94^{\circ} \mathrm{C} 4 \mathrm{~min}, 94^{\circ} \mathrm{C} 30 \mathrm{~s}, 56^{\circ} \mathrm{C} 30 \mathrm{~s}, 72^{\circ} \mathrm{C} 1 \mathrm{~min} ; 25$ 个循 环, $72^{\circ} \mathrm{C} 10 \mathrm{~min}$ 。将同一份DNA样本的 4 种不同荧光 PCR产物合并后用ABI 3730XL遗传分析仪进行毛 细管电泳检测。用 GeneMapper version 4.0 软件 (Applied Biosystems)进行等位基因判读。

\section{4 数据分析和DNA指纹数据库的构建}

用PowerMarker V3.25软件(Liu \& Muse, 2005) 统计每对引物扩增 1,409 份野生莲和58份美洲黄莲 两组样品的等位基因数, 计算每对引物标记 72 个品 种的等位基因数、基因型数和多态性信息含量 (polymorphism information content, PIC)。参考
Botstein等(1980)对 $P I C$ 值的判定标准, $P I C>0.5$ 为高 多态性, $0.25<P I C<0.5$ 为中多态性, $P I C<0.25$ 为低多 态性。根据上述统计结果, 参照玉米(赵久然和王凤 格, 2009)等DNA指纹条码的选择标准, 确定作为莲 品种DNA指纹条码的引物。

用以下方法构建 72 个莲品种的DNA指纹图谱, 将每个品种通过不同引物标记获得等位基因片段 的大小, 按从小到大的顺序依次用阿拉伯数字编 码。如果等位基因数超过 1 位数 9 以上, 则用个位数 字带下划线表示, 如第10个等位基因用“侻”, 第11个 等位基因用“依”表示, 这样保证所有样品DNA条码 的位数相同。

\section{2 结果}

\subsection{SSR分子标记多态性}

20 对 nSSR 引物扩增结果显示, 有 4 对引物 (NS050、SSR047、SSR072和SSR053)在栽培品种 出现3-4条峰现象, SSR013扩增缺失数据较多, 故 舍弃这 5 对引物, 最终确定 15 对 nSSR 引物作为 DNA鉴定的条码(表1, 附录2)。15对nSSR标记检测 结果显示, 1,409 份野生莲群体样本共有 118 个等位 基因, 58份美洲黄莲共有45个, 其中种间共享等位 基因10个(包括NS034、SSR016、SSR040和SSR074 共4对引物)。15对nSSR标记72个品种共检测到94 个等位基因(平均6.27个), 其中 11 个属于美洲黄莲 位点, 65 个属于野生莲位点, 10 个种间共享, 8 个特 有等位基因。共有19个品种检测到含有美洲黄莲遗 传组分 (附录2), 其中 ‘希望”仅检测到 2 对为最少; “蝶恋花”和 ‘冰心”各有 11 对引物为最多。15对nSSR 引物扩增 72 个品种的 PIC 值介于 $0.3899-0.8023$ 之 间(平均值 0.5748 )。其中有 11 对引物的 PIC值大于 0.5 (表1)。本研究所有15对引物均为中多态性至高 多态性。

6对cPSSR 引物标记全部样本结果显示, 其中 Lotus17和Lotus12具有相对高的种间和种内多态性, 可明显区分品种的母系来源(表1)。6对 cpSSR引物标 记72个莲品种结果, Lotus17有3种单倍型(2种为美 洲黄莲特有, 1 种为莲特有); Lotus12有10种单倍型 ( 2 种为美洲黄莲特有, 8 种为莲特有)。这 2 对 $c p S S R$ 引物同时检测到 8 个品种母系起源于美洲黄莲谱系, 64 个品种母系起源于莲谱系。因此, 我们优选这2 对cPSSR引物作为检测母系遗传的DNA条码。 


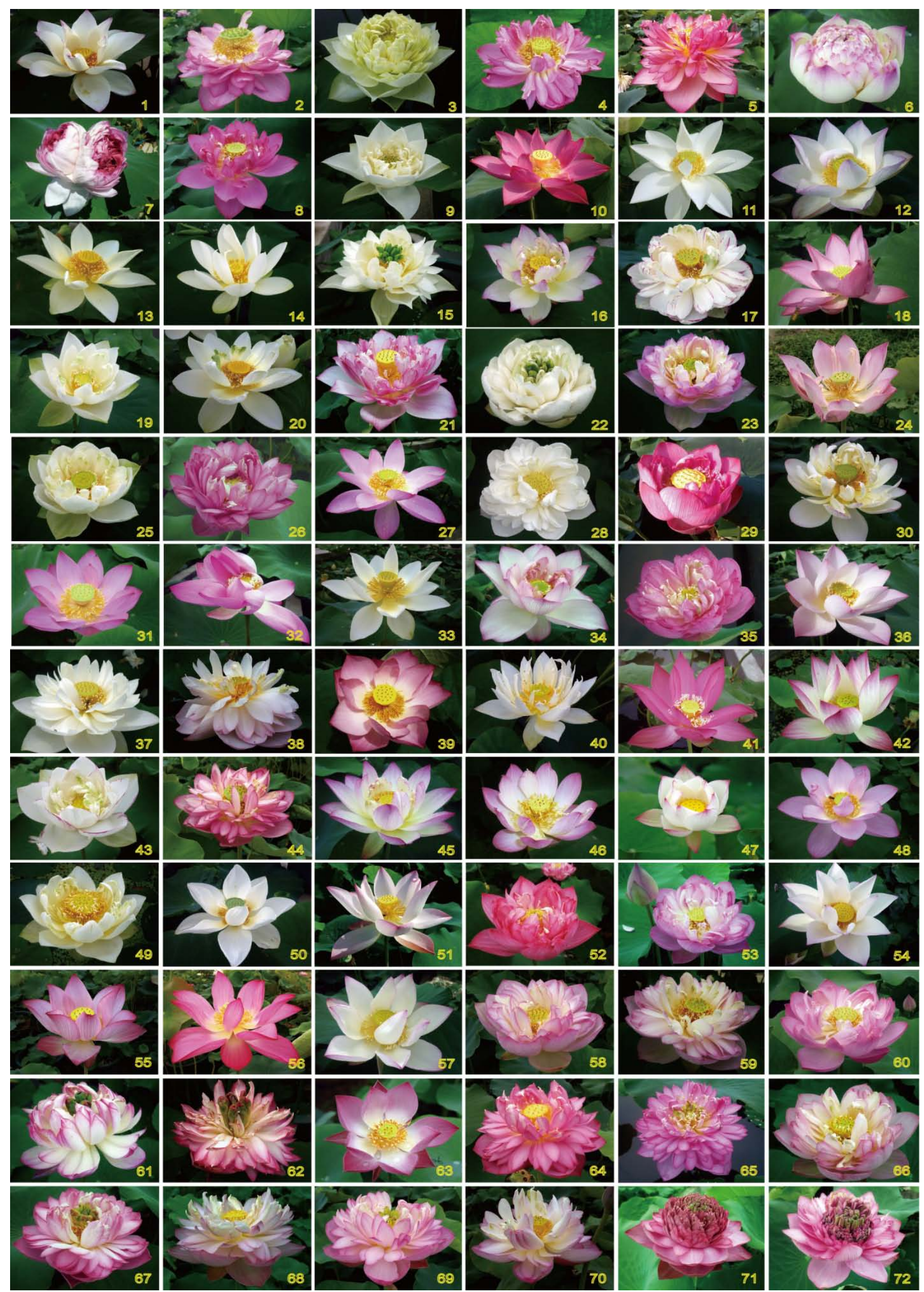




\section{2 不同引物组合的鉴别效率}

17 对微卫星标记结果显示, 有 36 个品种 (占 47.22\%)具有至少 1 个特有基因型, 仅用 1 对引物即 可区分。 1 个品种(“绿如意”)具有 4 个特有基因型, 5
个品种(“建选17号”、“古代莲”、“沂蒙颂”、“黄舞妃” 和 “伯里夫人’)具有 3 个特有基因型。单个引物 SSR040 的鉴别效率最高, 可区分 12 个品种 (占 16.7\%)(图1: 1-12), 2对引物组合(SSR040 + SSR030)

表1 17对SSR核心引物扩增的72个莲品种的等位基因数、基因型数及多态信息含量(PIC)

Table 1 Number of alleles, number of genotype, and polymorphic information content (PIC) of 17 core SSR primers

\begin{tabular}{|c|c|c|c|c|c|c|c|c|}
\hline \multirow[t]{2}{*}{$\begin{array}{l}\text { 引物 } \\
\text { Primer }\end{array}$} & \multicolumn{5}{|c|}{$\begin{array}{c}72 \text { 个品种莲 } \\
72 \text { lotus cultivars } \\
\end{array}$} & \multirow{2}{*}{$\begin{array}{l}\text { 1,409份野生莲 } \\
\text { 等位基因数 } \\
\text { Alleles number } \\
\text { in } 1,409 \text { samples } \\
\text { of } N \text {. nucifera }\end{array}$} & \multirow{2}{*}{$\begin{array}{l}\text { 58份美洲黄莲 } \\
\text { 等位基因数 } \\
\text { Alleles number } \\
\text { in } 58 \text { samples } \\
\text { of } N . \text { lutea }\end{array}$} & \multirow{2}{*}{$\begin{array}{l}\text { 种间共享等 } \\
\text { 位基因数 } \\
\text { Shared alleles } \\
\text { between } \\
\text { species }\end{array}$} \\
\hline & $\begin{array}{l}\text { 等位基因数 } \\
\text { Alleles number }\end{array}$ & $\begin{array}{l}\text { 基因型数 } \\
\text { Genotype } \\
\text { number }\end{array}$ & $\begin{array}{l}\text { 特有等位 } \\
\text { 基因数 } \\
\text { Specific allele } \\
\text { number }\end{array}$ & PIC & $\begin{array}{l}\text { 有 N. lutea成分的品种数 } \\
\text { Number in cultivars of } \\
\text { Nelumbo lutea }\end{array}$ & & & \\
\hline $\operatorname{SSR}^{2} 30^{[1]^{* *}}$ & 10 & 26 & 0 & 0.8023 & 0 & 15 & 2 & 0 \\
\hline SSR040 $0^{[1]}$ & 12 & 24 & 2 & 0.7426 & 0 & 10 & 5 & 2 \\
\hline $\operatorname{SSR} 064^{[1]}$ & 8 & 18 & 0 & 0.7199 & 4 & 15 & 1 & 0 \\
\hline SSR016 ${ }^{[1]}$ & 9 & 18 & 1 & 0.6576 & 6 & 16 & 6 & 3 \\
\hline SSR088 $^{[1]}$ & 5 & 10 & 0 & 0.6284 & 0 & 4 & 2 & 0 \\
\hline Nelumbo14 $4^{[2]}$ & 6 & 12 & 0 & 0.6051 & 11 & 5 & 5 & 0 \\
\hline $\mathrm{NS} 034^{[3]}$ & 8 & 14 & 1 & 0.6022 & 0 & 9 & 5 & 4 \\
\hline SSR067 $7^{[1]}$ & 5 & 9 & 0 & 0.5846 & 0 & 6 & 2 & 0 \\
\hline SSR285 ${ }^{[1]}$ & 7 & 12 & 3 & 0.5795 & 0 & 6 & 4 & 0 \\
\hline SSR074 ${ }^{[1]}$ & 7 & 9 & 0 & 0.5379 & 0 & 10 & 3 & 1 \\
\hline Nelumbo13 $^{[2]}$ & 4 & 6 & 1 & 0.5010 & 19 & 5 & 2 & 0 \\
\hline SSR472 ${ }^{[1]}$ & 3 & 5 & 0 & 0.4575 & 12 & 3 & 1 & 0 \\
\hline SSR049 ${ }^{[1]}$ & 3 & 4 & 0 & 0.4134 & 0 & 7 & 1 & 0 \\
\hline SSR482 ${ }^{[1]}$ & 3 & 5 & 0 & 0.4003 & 0 & 4 & 5 & 0 \\
\hline SSR045 ${ }^{[1]}$ & 4 & 7 & 0 & 0.3899 & 0 & 3 & 1 & 0 \\
\hline Lotus12 ${ }^{[4]}$ & 10 & 10 & 0 & - & 8 & 16 & 3 & 0 \\
\hline Lotus17 ${ }^{[4]}$ & 3 & 3 & 0 & - & 8 & 1 & 2 & 0 \\
\hline
\end{tabular}

[1]-[4]代表引物的文献来源。[1]-[4] are references of the primers. [1] Yang et al (2012); [2] Tian et al (2008); [3] Kubo et al (2009); [4] Xue et al (2012).

\section{图1 本研究中72个莲品种花的形态图}

Fig. 1 The floral morphologies of 72 lotus cultivars used in this study

1. 建选17号“Jian Xuan Shiqihao’; 2. 沂蒙颂‘Yimeng Song’; 3. 绿如意“Lvruyi’; 4. 蟹爪红‘Xiezhua Hong’; 5. 卓越‘Zhuoyue’; 6. 红唇‘Hong Chun’; 7. 千瓣莲‘Qianban Lian’; 8. 红樱桃‘Hongyingtao’; 9. 白苟药莲‘Bai Shaoyao Lian’; 10. 案头春‘Antou Chun’; 11. 一丈青‘Yizhangqing’; 12. 白湘莲“Baixianglian’; 13. 黄舞妃‘Huang Wu Fei’; 14. 冰心“Bing Xin’; 15. 珠峰翠影 'Zhufeng Cuiying’; 16. 新红‘Xin Hong’; 17. 大洒锦‘Dasajin’; 18. 中日友谊莲‘Zhong-ri Youyi Lian’; 19. 心洁‘Xin Jie’; 20. 晨 光“Chenguang’; 21. 星空牡丹“Xingkong Mudan’; 22. 枚子碗莲“Zhizi Wanlian’; 23. 粉千叶“Fen Qianye’; 24. 日出‘Richu’; 25. 素质冰姿‘Suzhi Bing Zi’; 26. 红牡丹‘Hong Mudan’; 27. 古代莲“Gudai Lian’; 28. 白雪公主‘Baixue Gongzhu’; 29. 紫重阳‘Zi Chongyang’; 30. 伯里夫人 ‘Boli Furen’; 31. 玫园秀色 ‘Meiyuan Xiu Se’; 32. 丹鹤‘Dan He’; 33. 金凤展翅‘Jinfeng Zhanchi’; 34. 英华‘Yinghua’; 35. 杏花春雨 ‘Xinghua Chunyu’; 36. 喜笑颜开‘Xixiaoyankai’; 37. 普者黑白荷‘Puzhehei Baihe’; 38. 粉楼春 'Fenlou Chun’; 39. 建乡壮士‘Jianxiang Zhuangshi’; 40. 希望‘Xiwang’; 41. 红领巾‘Honglingjin’; 42. 丹凤朝阳'Dangfeng Chaoyang’; 43. 小洒锦‘Xiaosajin’; 44. 普者黑红荷‘Puzhehei Honghe’; 45. 蝶恋花‘Die Lian Hua’; 46. 小精灵‘Xiao Jingling’; 47. 红边玉蝶‘Hongbian Yudie’; 48. 佛见笑“Fojianxiao’; 49. 荣莺‘Yingying’; 50. 奔月 ‘Benyue’; 51. 粉娃莲‘Fenwalian’; 52. 睡 美人‘Shui Meiren’; 53. 东湖夕照‘Donghu Xi Zhao’; 54. 粉青莲‘Fen Qing Lian’; 55. 红湘莲‘Hongxianglian’; 56. 姬妃莲‘Jifei Lian’; 57. 点额妆‘Dian E Zhuang’; 58. 曙光‘Shuguang’; 59. 露半唇‘Lu Ban Chun’; 60. 桃红宿雨‘Tao Hong Su Yu’; 61. 春桃 ‘Chun Tao’; 62. 彩蝶‘Cai Die’; 63. 小佛手‘Xiao Foshou’; 64. 飞虹‘Fei Hong’; 65. 红楼‘Hong Lou’; 66. 粉霞‘Fen Xia’; 67. 丹 绣球‘Dan Xiuqiu’; 68. 钗头凤‘Chai Tou Feng’; 69. 红戞托珠‘Hong Zhan Tuo Zhu’; 70. 平山芙蓉‘Pingshan Furong’; 71. 中山红 台'Zhongshan Hongtai’; 72. 至尊千瓣‘Zhizun Qianban’ 
可区分38个品种(占52.78\%)(图1：1-38), 3对引物组 合 (SSR040+SSR030+SSR016) 可区分 57 个品种 (79.17\%)(图 1: 1-57)。最佳引物组合 (Lotus12+ SSR040+SSR030+SSR016+SSR285+NS034+Nelumb o14+SSR074) 共 8 对可完全区分开 68 个品种 (占 94.44\%)(图1: 1-68)。其余4个品种用全部17对引物 也只能区分到组水平: 第一组是“红戞托珠”和“平山 芙蓉’(图1: 69-70), 第二组是“中山红台’和‘至尊千 瓣”图1: 71-72)。即每个组内2个品种用全部17对引 物标记时仍具有相同的基因型。

\section{3 莲品种DNA指纹图谱的构建}

15 对nSSR二倍体共有 30 位数字, 2 对 $\mathrm{cpSSR}$ 单倍 型共有 2 位数字, 全部17对引物扩增DNA条码由 32 位数字组成。将每个品种通过17对引物标记所获得 的基因型片段大小直接进行编码(表2), 构建 72 个品 种莲的DNA指纹图谱(附录1)。结果表明, 68个品种 具有特异性DNA指纹。“中山红台”和“至尊千瓣”具 有相同的DNA指纹, “红戞托珠”和“平山芙蓉”具有 相同的DNA指纹。

\section{3 讨论}

\section{1 莲品种遗传背景参照的选择}

由于栽培莲的历史悠久, 分布范围广泛, 不同
地区甚至国家之间的交流频繁，品种来源及其关系 非常复杂。我国的莲品种资源可归纳为两大类谱系 起源: (1)种间杂交谱系。莲属2个种在更新世(约1.5 Ma)分化(Xue et al, 2012), 仅存在地理隔离, 无生 殖隔离, 杂交可育。如“友谊牡丹莲”和“黄舞妃”等都 是种间杂交育成。还有些品种是从天然杂交种子中 选育, 不清楚是否是种间杂交而来。本研究中检测 的19个种间杂交品种中 (附录2), 仅有 6 个已知为种 间杂交起源, 其余13个均为本研究检测查明。(2)莲 谱系。属于莲种内谱系的品种, 仅有少数亲本来源 明确, 绝大多数未知。例如, “千瓣莲”、“宜良千瓣” 和‘中山红台”等一些雄荵完全瓣化、不能结实的千 瓣型和重台型品种，属于我国民间流传下来的早期 传统品种, 具体来源很难考证。本研究选择58份美 洲黄莲和来自不同地理分布点的1,409份野生莲群 体材料作为遗传背景参照, 有利于分析判断种间和 种内不同地域的遗传组分, 为后续揭示品种起源研 究等奠定基础。此外, 本研究将2对叶绿体微卫星引 物作为DNA指纹的条码，可有效鉴定母系来源。

\section{2 核心引物的使用数量}

确定核心引物的基本原则主要包括: 扩增成功 率高、条带清晰、变异位点容易区分、多态性高、 染色体定位清楚、引物之间尽量不连锁等(赵久然和

表2 17对SSR核心引物等位基因编码标准

Table 2 Alleles encoded standard of 17 core SSR primers

\begin{tabular}{|c|c|c|c|c|c|c|c|c|c|c|c|c|}
\hline 引物 & & & & & & & Code & & & & & \\
\hline Primer & 1 & 2 & 3 & 4 & 5 & 6 & 7 & 8 & 9 & $\underline{0}^{\mathrm{a}}$ & $\underline{1}$ & $\underline{2}$ \\
\hline Lotus12 & $374^{*}$ & 375 & $379^{*}$ & 380 & 385 & 390 & 395 & 400 & 410 & 415 & & \\
\hline SSR040 & $205^{+}$ & 211 & $213^{*}$ & 215 & 217 & 223 & 225 & 229 & 231 & 233 & 235 & $237^{+}$ \\
\hline SSR030 & $130^{*}$ & 142 & 145 & 148 & 151 & 154 & 160 & 163 & 166 & 169 & & \\
\hline SSR016 & $190^{*}$ & 215 & 218 & 221 & 224 & 233 & 236 & 242 & $254^{+}$ & & & \\
\hline SSR285 & 262 & 272 & 274 & 276 & $292^{+}$ & $300^{+}$ & $316^{+}$ & & & & & \\
\hline NS034 & 98 & 102 & 104 & 112 & 114 & 116 & 118 & $124^{+}$ & & & & \\
\hline Nelumbo14 & 147 & 149 & 151 & 153 & $171^{*}$ & $173^{*}$ & & & & & & \\
\hline SSR074 & 154 & 160 & 163 & 169 & 172 & 178 & 181 & & & & & \\
\hline SSR049 & 233 & 245 & 248 & & & & & & & & & \\
\hline SSR064 & $178^{*}$ & 187 & 190 & 193 & 199 & 202 & 205 & 208 & & & & \\
\hline SSR067 & 238 & 244 & 247 & 253 & $262^{*}$ & & & & & & & \\
\hline SSR088 & 285 & 297 & 301 & $305^{*}$ & $309^{*}$ & & & & & & & \\
\hline SSR482 & 172 & 200 & 203 & & & & & & & & & \\
\hline Lotus17 & $231^{*}$ & 242 & $246^{*}$ & & & & & & & & & \\
\hline Nelumbo13 & $142^{*}$ & 146 & $156^{+}$ & 160 & & & & & & & & \\
\hline SSR045 & $187^{*}$ & 211 & 214 & 217 & & & & & & & & \\
\hline SSR472 & $196^{*}$ & 223 & 229 & & & & & & & & & \\
\hline
\end{tabular}

*只来自美洲黄莲; ${ }^{+}$只来自品种莲。 ${ }^{\mathrm{a}}$ 表示等位基因数加上 10 , 如 1 表示第 11 号等位基因。

*Alleles from Nelumbo lutea; ${ }^{+}$Alleles from lotus cultivars. ${ }^{a}$ indicates that the number should plus 10, e.g. 1 represents $11(1+10=11)$. 
王凤格, 2009; 赵久然等, 2015)。由于不同品种类群 的遗传背景不同, 核心引物数量各异。例如, 18对核 心引物可区分105个甜瓜品种(系) (宋海斌等, 2012); 47 对核心引物区可分 184 个甘蓝型油菜品种(赖运平 等, 2014); 而40对引物才能将51个新陆早棉花品种 完全区分开, 说明这些棉花品种的遗传多样性狭窄 (聂新辉等, 2014)。

综合分析表明, 本研究中除多态性较低的引物 SSR045和 SSR 472外, 其余 15 对 (13对 nSSR 和 2 对 (pSSR)均可作为核心引物。尽管最少 8 对引物就可 以完全分开 68 个品种, 但随着品种数量的增加, 分 辨率也会随之下降。因此, 核心引物需要不断补充 完善。例如, 鉴定体系最完善的玉米核心引物已由 20对基本核心引物(NY/T 1432-2007)增加到40对 (NY/T 1432-2014)。另外, 本研究中13对nSSR引物 均不在连锁群中(Yang et al, 2012), 但这些引物的染 色体定位目前尚不清楚, 但古莲全基因组测序已经 完成了 $86.7 \%$, 并已完成基因组框架图谱的构建 (Ming et al, 2013), 染色体定位工作有待于后续完 成。

\section{3 莲品种真实性、稳定性和一致性的判定标准}

绝大多数物种的品种都是以种子进行扩繁的, 由于有性生殖过程中发生DNA重组, 难免会影响种 子的纯度, 使DNA指纹检测品种一致性和稳定性的 判定标准难度增加。以玉米为例: (1)品种一致性的 检测标准。一个品种一次至少随机检测20个样本, 用 10 对核心引物标记, 如果单个和所有引物位点平 均值的一致性大于 $95 \%$, 可认为品种的一致性高, 介于 85-95\%之间为中, 小于 $85 \%$ 为差(赵久然和王 凤格, 2009)。(2)品种真实性的判定标准。首先用20 对核心引物标记位点比较, 品种间差异位点数 $\geq 2$, 判定为不同品种; 品种间差异位点数 $=1$, 判定为 相近品种; 品种间差异位点数 $=0$, 判定为疑同品 种。如果是疑同品种, 则需要进一步用20对扩展核 心引物进行检测, 如果品种间的位点完全相同, 判 定为相同品种或极近似品种 (赵久然和王风格, 2009)。

莲品种的扩繁是通过无性繁殖(种藕)方式实现 的, 不发生DNA重组, 由于发生突变的概率非常低, 理论上同一个莲品种克隆繁殖的所有不同个体应 该具有完全相同的DNA指纹图谱。从克隆繁殖的意 义上来看, 莲品种DNA指纹的一致性和稳定性优于
玉米、水稻和大豆等通过有性繁殖方式扩繁的类群, 莲品种DNA指纹具有较高的一致性和稳定性, 我们 建议判定同一个品种的标准应该是所有位点都 $100 \%$ 相同。判定品种的真实性, 如果两个品种用 15 对核心引物检测的所有基因型都相同，认为是亲缘 关系较近或疑同品种, 需要用更多位点检测。

本研究中, 有两组内部未能区分的 4 个品种, 组内 2 个品种的形态也非常相似: ‘红盏托珠’ 和‘平 山芙蓉”都属于粉色重瓣型(图1: 69-70), “至尊千瓣” 与“中山红台”都属于粉红色重台型(图1: 71-72)。表 明这 2 组品种内部遗传关系非常近, 或者为疑似同 一个品种, 有待于进一步检测。这种现象在其他品 种中也同样出现过。如赵胜杰等(2014)用23个SSR 引物标记 54 个无籽西瓜品种时, 有3组内部2个品种 之间无法区分; Madhou等(2013)用11对SSR引物标 记88个来自西班牙、毛里求斯和法国的荔枝 (Litchi chinensis)栽培品种, 仅得到42份不同的DNA指纹, 澄清了一些同物异名品种; 陈昌文等(2011)用16对 SSR引物标记237份中国桃品种, 得到202份种质的 DNA指纹, 还有35份不能区分, 原因之一可能是这 些品种之间遗传关系非常近, 也有些是芽变品种 (即SSR标记适合分辨杂交起源的品种, 很难区分芽 变及诱变等方式起源的品种)。

\section{4 莲品种DNA指纹鉴定的应用前景}

中国有记载的品种莲达 800 多个, 在民间还有 一些品种并没有被记录。长期以来, 我国对莲品种 专利权方面的保护力度非常不够, 莲品种一旦从培 育者手中流出, 基本处于无专利保护状态。单纯依 据形态鉴定很难实现对品种的规范分类和品种专 利权的有效保护。国际上应用DNA指纹技术维护品 种专利权已有不少成功案例。例如, Archak等(2007) 筛选了 8 个 SSR标记位点检测印度香米(Oryza sativa) 的纯度, 如果掺假达 $1 \%$ 以上就可以被检测出 来; Faria等(2008)用 2 个SSR标记位点能够检测来自 葡萄牙 4 个葡萄(Vitis vinifera) 品种的组成及其含量, 成为检测葡萄酒原料是否纯正的技术手段。因此, 我们建议采用形态特性与DNA指纹图谱相结合作 为对品种的鉴定标准, 实现对莲品种的准确鉴定, 有效保护品种专利权，具有良好的应用前景。

\section{参考文献}

Archak S, Lakshminarayanareddy V, Nagaraju J (2007) High-throughput multiplex microsatellite marker assay for 
detection and quantification of adulteration in Basmati rice (Oryza sativa). Electrophoresis, 28, 2396-2405.

Botstein D, White RL, Skolnick M, Davis RW (1980) Construction of a genetic linkage map in man using restriction fragment length polymorphisms. American Journal of $\mathrm{Hu}-$ man Genetics, 32, 314-331.

Chen CW, Cao K, Wang LR, Zhu GR, Fang WC (2011) Molecular ID establishment of main China peach varieties and peach related species. Scientia Agricultura Sinica, 44, 2081-2093. (in Chinese with English abstract) [陈昌文, 曹 珂, 王力荣, 朱更瑞, 方伟超 (2011) 中国桃主要品种资 源及其野生近缘种的分子身份证构建. 中国农业科学, 44, 2081-2093.]

Faria MA, Nunes E, Oliveira MBPP (2008) Relative quantification of Vitis vinifera L. varieties in musts by microsatellite DNA analysis. European Food Research and Technology, 227, 845-850.

Jeffreys AJ, Wilson V, Thein SL (1985a) Individual-specific 'fingerprints' of human DNA. Nature, 316, 76-79.

Jeffreys AJ, Wilson V, Thein SL (1985b) Hypervariable 'Minisatellite' regions in human DNA. Nature, 314, 67-73.

Kubo N, Hirai M, Kaneko A, Tanaka D, Kasumi K (2009) Development and characterization of simple sequence repeat (SSR) markers in the water lotus (Nelumbo nucifera). Aquatic Botany, 90, 191-194.

Lai YP, Wang LR, He QL, Zhang ZF, Zhang XM, Du YY, Yu $Y$ (2014) Screening of SSR core primers and fingerprinting construction of Brassica napus L. Southwest China Journal of Agricultural Sciences, 27, 2290-2299. (in Chinese with English abstract) [赖运平, 王丽容, 何巧林, 张浙峰, 张新 明, 堵苑苑, 余毅 (2014) 甘蓝型油菜核心SSR引物笁选 及指纹图谱构建. 西南农业学报, 27, 2290-2299.]

Li Y, Svetlana P, Yao JX, Li CS (2014) A review on the taxonomic, evolutionary and phytogeographic studies of the lotus plant (Nelumbonaceae: Nelumbo). Acta Geologica Sinica, 88, 1252-1261.

Liu K, Muse SV (2005) PowerMarker: an integrated analysis environment for genetic marker analysis. Bioinformatics, 21, 2128-2129.

Madhou M, Normand F, Bahorun T, Hormaza JI (2013) Fingerprinting and analysis of genetic diversity of litchi (Litchi chinensis Sonn.) accessions from different germplasm collections using microsatellite markers. Tree Genetics \& Genomes, 9, 387-396.

Miura K, Ikegami S (2012) Photographic Reference Book of World Lotus Flowers. Bensei Publish Company, Tokyo. (in Japan)

Ming R, VanBuren R, Liu YL, Yang M, Han YP, Li LT, Zhang Q, Kim MJ, Schatz MC, Campbell M, Li JP, Bowers JE, Tang HB, Lyons E, Ferguson AA, Narzisi G, Nelson DR, Blaby-Haas CE, Gschwend AR, Jiao YN, Der JP, Zeng FC, Han J, Min XJ, Hudson KA, Singh R, Grennan AK, Karpowicz SJ, Watling JR, Ito K, Robinson SA, Hudson ME, Yu QY, Mockler TC, Carroll A, Zheng Y, Sunkar R, Jia RZ, Chen NC, Arro J, Wai CM, Wafula E, Spence A, Han YN,
Xu LM, Zhang JS, Peery R, Haus MJ, Xiong WW, Walsh JA, Wu J, Wang ML, Zhu YJ, Paull RE, Britt AB, Du CG, Downie SR, Schuler MA, Michael TP, Long SP, Ort DR, Schopf JW, Gang DR, Jiang N, Yandell M, dePamphilis CW, Merchant SS, Paterson AH, Buchanan BB, Li SH, Shen-Miller J (2013) Genome of the long-living sacred lotus (Nelumbo nucifera Gaertn.). Genome Biology, 14, R41.

Nie XH, You CY, Li XF, Qin JH, Huang C, Guo HL, Wang XQ, Zhao WX, Lin ZX (2014) Construction of DNA fingerprinting and analysis of genetic diversity for Xinluzao cotton varieties. Acta Agronomica Sinica, 40, 2104-2117. (in Chinese with English abstract) [聂新辉, 尤春源, 李晓 方, 秦江鸿, 黄聪, 郭欢乐, 王夏青, 赵文霞, 林忠旭 (2014) 新陆早棉花DNA指纹图谱的构建及遗传多样性分 析. 作物学报, 40, 2104-2117.]

Song HB, Cui XB, Ma HY, Zhu ZC, Luan FS (2012) Construction of DNA fingerprint database based on SSR marker for varieties (Lines) of Cucumis melo L. Scientia Agricultura Sinica, 45, 2676-2689. (in Chinese with English abstract) [宋海斌, 崔喜波, 马鸿艳, 朱子成, 橸非时 (2012) 基于 SSR标记的甜瓜品种(系)DNA指纹图谱库的构建. 中国农 业科学, 45, 2676-2689.]

Tian HL, Chen XQ, Wang JX, Xue JH, Wen J, Mitchell G, Zhou SL (2008) Development and characterization of microsatellite loci for lotus (Nelumbo nucifera). Conservation Genetics, 9, 1385-1388.

Wang QC, Zhang XY (2005) Lotus Flower Cultivars in China. China Forestry Publishing House, Beijing. (in Chinese) [王 其超, 张行言 (2005) 中国荷花品种图志. 中国林业出版 社, 北京.]

Wu ZY, Lu AM, Tang YC, Chen ZD, Li DZ (2003) The Families and Genera of Angiosperms in China. Science Press, Beijing. (in Chinese) [吴征镒, 路安民, 汤彦承, 陈之端, 李德铢 (2003) 中国被子植物科属综论. 科学出版社, 北 京.]

Xue JH, Dong WP, Zhou SL (2012) Nelumbonaceae: Systematic position and species diversification revealed by the complete chloroplast genome. Journal of Systematics and Evolution, 50, 477-487.

Xue JH, Wang S, Zhou SL (2012) Polymorphic chloroplast microsatellite loci in Nelumbo (Nelumbonaceae). American Journal of Botany, 99, E240-E244.

Yang M, Han YN, VanBuren R, Ming R, Xu LM, Han YP, Liu YL (2012) Genetic linkage maps for Asian and American lotus constructed using novel SSR markers derived from the genome of sequenced cultivar. BMC Genomics, 13, 653.

Zhang XY, Chen LQ, Wang QC (2011) New Lotus Flower Cultivars in China I. China Forestry Publishing House, Beijing. (in Chinese) [张行言, 陈龙清, 王其超 (2011)中国荷 花新品种图志I. 中国林业出版社, 北京.]

Zhao JR, Wang FG (2009) Research and Application of Maize Cultivars' DNA Fingerprint Identification Technology. China Agricultural Science and Technology Press, Beijing. (in Chinese) [赵久然, 王凤格 (2009) 玉米品种DNA指纹 
鉴定技术研究与应用. 中国农业科学技术出版社, 北京.]

Zhao JR, Wang FG, Yi HM, Tian HL, Yang Y (2015) Progress of construction of Chinese maize varieties standard DNA fingerprint database. Crops, 165, 1-6. (in Chinese with English abstract). [赵久然, 王风格, 易红梅, 田红丽, 杨扬 (2015) 我国玉米品种标准DNA指纹库构建研究及应用进 展. 作物杂志, (165), 1-6.]

Zhao SJ, Zhu HJ, Lu XQ, He N, Liu WG (2014) Studies on
DNA fingerprinting and genetic diversity of seedless watermelon (Citrullus lanatus) varieties using core simple sequence repeat (SSR) markers. Journal of Agricultural Biotechnology, 22, 188-194. (in Chinese with English abstract) [赵胜杰, 朱红菊, 路绪强, 何楠, 刘文革 (2014) 利用核 心简单重复序列(SSR)标记分析无䊏西瓜品种的DNA指 纹及遗传多样性. 农业生物技术学报, 22, 188-194.]

(责任编委: 王艇 责任编辑: 时意专)

\section{附录 Supplementary Material}

附录1 72 个莲品种的DNA指纹编码

Appendix 1 DNA fingerprint codes of 72 lotus cultivars

http://www.biodiversity-science.net/fileup/PDF/2015157-1.pdf

附录2 ‘千瓣莲” SSR030(a)和NS034(b)引物毛细管电泳检测峰图

Appendix 2 Capillary electrophoresis profiles of 'Qianbanlian' at fluorescent marker locus SSR030 (a) and NS034 (b)

http://www.biodiversity-science.net/fileup/PDF/2015157-2.pdf 
薛建华, 姜莉, 马晓林, 丙艳红, 赵思晨, 马克平. 莲品种 DNA 指纹图谱的构建. 生物多样性, 2016, 24 (1), 3-11. http://www.biodiversity-science.net/CN/10.17520/biods.2015157

附录1 72个莲品种的DNA指纹编码

Appendix 1 DNA fingerprint codes of 72 lotus cultivars

\begin{tabular}{|c|c|c|c|}
\hline $\begin{array}{l}\text { 编号 } \\
\text { Number }\end{array}$ & $\begin{array}{l}\text { 种质名称 } \\
\text { Germplasm nc }\end{array}$ & & $\begin{array}{l}\text { DNA 指纹编码a } \\
\text { DNA fingerprint code }\end{array}$ \\
\hline 1 & 建选17号 & Jian Xuan Shiqihao & 62522881118444411223422112222233 \\
\hline 2 & 沂蒙颂 & Yimeng Song & 51933343315234612272313332242323 \\
\hline 3 & 绿如意* & Lvruyi & 46936141756461411223512112121233 \\
\hline 4 & 蟹爪红** & Xiezhua Hong & $33 \underline{0^{\mathrm{b}} 13461115234612483522113122233}$ \\
\hline 5 & 卓越* & Zhuoyue & 42637583711261622263323222142222 \\
\hline 6 & 红唇* & Hong Chun & 42ㅁ38881316331611443312122121223 \\
\hline 7 & 千瓣莲 & Qianban Lian & $74 \underline{1} 37331415334633242423132342223$ \\
\hline 8 & 红樱桃 & Hongyingtao & $4 \underline{11} 35343315224622663333222442323$ \\
\hline 9 & 白药药莲 & Bai Shaoyao Lian & 56667443355336622664413222442233 \\
\hline 10 & 案头春 & Antou Chun & 53848341355234612443311122242323 \\
\hline 11 & 一丈青 & Yizhangqing & 57939473315244622222412222442222 \\
\hline 12 & 白湘莲 & Baixianglian & 97733481317336622564411122242233 \\
\hline 13 & 黄舞妃*** & Huang Wu Fei & 35514181527451311221314113121213 \\
\hline 14 & 冰心** & Bing Xin & 38817181512351411113524113121212 \\
\hline 15 & 珠峰翠影** & Zhufeng Cuiying & 32278481315251411223323123122212 \\
\hline 16 & 新红* & Xin Hong & 52214441525251411123514112121213 \\
\hline 17 & 大洒锦 & Dasajin & 42944371315224622252212122242223 \\
\hline 18 & 中日友谊莲 & Zhong-ri Youyi Lian & 52880461311236622482322122242322 \\
\hline 19 & 心洁* & Xin Jie & 42947441155461411223312112122212 \\
\hline 20 & 晨光** & Chenguang & $1 \underline{00} 14331635221622552514111141212$ \\
\hline 21 & 星空牡丹 & Xingkong Mudan & 52227891117244411222312112242233 \\
\hline 22 & 柧子碗莲 & Zhizi Wanlian & 52837481115334411443312112222223 \\
\hline 23 & 粉千叶 & Fen Qianye & 52877441255334612463312122222222 \\
\hline 24 & 日出 & Richu & 528600443315344612243312222222322 \\
\hline 25 & 素质冰姿 & Suzhi Bing Zi & 52236441355344612263411122242223 \\
\hline 26 & 红牡丹 & Hong Mudan & 52840341315226622243312122222322 \\
\hline 27 & 古代莲 & Gudai Lian & 98855444411226622662422222444422 \\
\hline 28 & 白雪公主 & Baixue Gongzhu & $5 \underline{0278441155236611452322112242222}$ \\
\hline 29 & 紫重阳 & Zi Chongyang & 52933441115236622243333112222323 \\
\hline 30 & 伯里夫人* & Boli Furen & 59917133316261633142525222141412 \\
\hline 31 & 玫园秀色 & Meiyuan Xiu Se & 52940341315224612243312122222323 \\
\hline 32 & 丹鹤 & Dan He & 088878223311236622882422222442222 \\
\hline 33 & 金凤展翅* & Jinfeng Zhanchi & 65513181527441411223514112121213 \\
\hline 34 & 英华* & Yinghua & 59937342715351622223422222242312 \\
\hline 35 & 杏花春雨 & Xinghua Chunyu & 50088441215334612462323122222322 \\
\hline 36 & 喜笑颜开 & Xixiaoyankai & 42977481311334411462322122242222 \\
\hline 37 & 普者黑白荷 & Puzhehei Baihe & 49949371315224622552212122242223 \\
\hline 38 & 粉楼春 & Fenlou Chun & $4 \underline{0288341315234612562222122242322}$ \\
\hline 39 & 建乡壮士 & Jianxiang Zhuangshi & 62233481357444612223413122242233 \\
\hline 40 & 希望** & Xiwang & 32867381315354612443313123122223 \\
\hline 41 & 红领巾** & Honglingjin & 32213361315244612283512123122213 \\
\hline 42 & 丹凤朝阳 $* *$ & Dangfeng Chaoyang & 32218463315236622883334223122222 \\
\hline 43 & 小酒锦 & Xiaosajin & 42949371315224622252212122242223 \\
\hline 44 & 普者黑红荷 & Puzhehei Honghe & 42949471315224622252212122242223 \\
\hline 45 & 蝶恋花* & Die Lian Hua & 52213131525251411113514112121213 \\
\hline 46 & 小精灵* & Xiao Jingling & 52218441512341411243522112121322 \\
\hline 47 & 红边玉蝶 & Hongbian Yudie & 52234481157342411263413112222233 \\
\hline
\end{tabular}


薛建华, 姜莉, 马晓林, 丙艳红, 赵思晨, 马克平. 莲品种 DNA 指纹图谱的构建. 生物多样性, 2016, 24 (1), 3-11. http://www.biodiversity-science.net/CN/10.17520/biods.2015157

\begin{tabular}{|c|c|c|c|}
\hline $\begin{array}{l}\text { 编号 } \\
\text { Number }\end{array}$ & $\begin{array}{l}\text { 种质名称 } \\
\text { Germplasn }\end{array}$ & me & $\begin{array}{l}\text { DNA指纹编码 }{ }^{a} \\
\text { DNA fingerprint code }\end{array}$ \\
\hline 48 & 佛见笑 & Fojianxiao & 29178343311336622262423222343322 \\
\hline 49 & 莺莺* & Yingying & 52234881512331411243511112122212 \\
\hline 50 & 奔月 & Benyue & 52978341315336622262223122242322 \\
\hline 51 & 粉娃莲 & Fenwalian & 52978441215334612462323122242322 \\
\hline 52 & 睡美人 & Shui Meiren & 59988341155344611243313112222322 \\
\hline 53 & 东湖夕照 & Donghu Xi Zhao & $59 \underline{17} 8441111334611333323112222222$ \\
\hline 54 & 粉青莲 & Fen Qing Lian & 82424891178344411223412112222233 \\
\hline 55 & 红湘莲 & Hongxianglian & 82424881178344411223412112222233 \\
\hline 56 & 姬妃莲 & Jifei Lian & 82867281317222622242412122242223 \\
\hline 57 & 点额妆 & Dian E Zhuang & 92233441311336622554411122442233 \\
\hline 58 & 曙光 & Shuguang & $52 \underline{1} 38341355344411262312122242222$ \\
\hline 59 & 露半唇 & Lu Ban Chun & 521383433555344612262312222442223 \\
\hline 60 & 桃红宿雨 & Tao Hong Su Yu & 59988441111336611443333112223322 \\
\hline 61 & 春桃 & Chun Tao & 59988442215336611443333222222322 \\
\hline 62 & 彩蝶 & Cai Die & 59988441255334611443333122222222 \\
\hline 63 & 小佛手 & Xiao Foshou & 59988441211334611443333122223322 \\
\hline 64 & 飞虹 & Fei Hong & 49938341155116622462333112222222 \\
\hline 65 & 红楼 & Hong Lou & 49938341155236622462333112222222 \\
\hline 66 & 粉霞 & Fen Xia & 59988441215335712462323122222322 \\
\hline 67 & 丹绣球 & Dan Xiuqiu & 59988441115334611443333122222222 \\
\hline 68 & 钗头风 & Chai Tou Feng & 69988441215334612462323122222322 \\
\hline 69 & 红盏托珠 & Hong Zhan Tuo Zhu & 59988441215334612462323122222322 \\
\hline 70 & 平山芙蓉 & Pingshan Furong & 59988441215334612462323122222322 \\
\hline 71 & 中山红台 & Zhongshan Hongtai & 44933663344334612222222222242233 \\
\hline 72 & 至尊千瓣 & Zhizun Qianban & 44933663344334612222222222242233 \\
\hline
\end{tabular}

*父系来自美洲黄莲谱系; **母系来自美洲黄莲谱系; '表示等位基因数加上10, 如1表示第11号等位基因编码。

*Male parent was from Nelumbo lutea ; * Female parent was from N. lutea. ${ }^{a}$ 引物编码顺序 Coding primers order: Lotus12, SSR040, SSR030, SSR016, SSR285, NS034, Nelumbo14, SSR074, SSR049, SSR064, SSR067, SSR088, SSR482, Lotus17, Nelumbo13, SSR045, SSR472. ${ }^{\text {b } T h e ~ n u m-~}$ ber should plus ten, e.g., 1 represents $11(1+10=11)$ of alleles.. 
薛建华, 姜莉, 马晓林, 丙艳红, 赵思晨, 马克平. 莲品种 DNA 指纹图谱的构建. 生物多样性, 2016, 24 (1), 3-11. http://www.biodiversity-science.net/CN/10.17520/biods.2015157
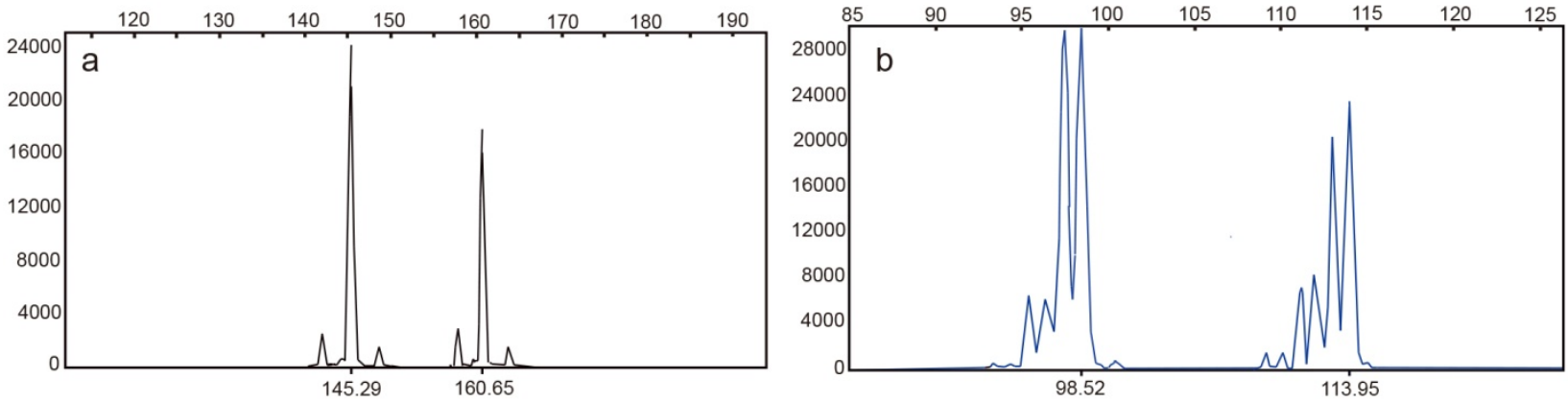

附录2 ‘千瓣莲’ SSR030 (a)和NS034 (b)荧光引物毛细管电泳检测峰图

Appendix 2 Capillary electrophoresis profiles of ‘Qianbanlian’ at fluorescent marker locus SSR030 (a) and NS034 (b) 